\title{
CRITICAL FLOW RESTRICTING ORIFICES
}

\section{D-Zero Engineering Note: 3740.510-EN-173}

\author{
C.H. Kurita
}

August 9, 1988

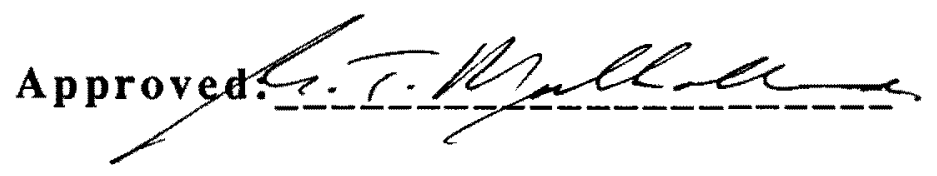




\section{INTRODUCTION}

The installation of flow restricting orifices in both the nitrogen gas and instrument air supply lines in the D-Zero Building limits the flow available to the various users. These orifices are strategically positioned along the lines such that no one user can monopolize the gas supply and deprive others of their flow required to operate.

\section{ORIFICE PLATE SIZING}

The following formula, taken from Marks' Standard Handbook for Mechanical Engineers, Ninth Edition, 1987, was used to size the openings for the orifice plates according to their given flow conditions.

$$
m=\left(0.53 * C * p_{1} * A_{2}\right) /\left(T_{1}{ }^{1 / 2}\right)
$$

Where: $m=$ mass of fluid flowing past a given section per $s, l b$ (here $\mathrm{m}=\mathrm{pq}, \mathrm{p}=$ density, $\mathrm{lb} / \mathrm{ft}^{3}, \mathrm{q}=$ volume of fluid flowing past section, $\mathrm{cfm}$ )

$\mathrm{C}=$ empirically determined coefficient of discharge (according to Marks': $\mathrm{C}=0.61$ for a sharp edged orifice, and $\mathrm{C}=0.80$ for a short tube)

$\mathrm{p}_{1}=$ pressure of fluid at inlet section, $1 \mathrm{~b} / \mathrm{ft}^{2}$ abs

$\mathrm{A}_{2}=$ area of orifice, $\mathrm{ft}^{2}$

$\left(A_{2}=\pi / 4 * D_{2}{ }^{2}, D_{2}=\right.$ diameter of the orifice, $\left.f t\right)$

$\mathrm{T}_{1}=$ inlet temperature, ${ }^{\circ} \mathrm{R}$

Upon using this formula, the following assumptions were made:

- fluid was air, an ideal gas

- reversible adiabatic expansion through the orifice

- inlet velocity<<velocity through the orifice and thus negligible

- ideal gas constant, $\mathrm{R}=53.3$

$-\mathrm{k}=\mathrm{C}_{\mathrm{p}} / \mathrm{C}_{\mathrm{v}}=1.3937$

- critical flow pressure, $\mathrm{p}_{\mathrm{m}}=0.53 * \mathrm{p}_{1}$ 
When the downstream pressure is less than the critical flow pressure, the flow rate becomes independent of the downstream pressure. This fact is later proven by the flow tests performed on the two different sample plates.

The required flow parameters are:
$\underline{\mathbf{A}}$
$\underline{\mathbf{B}}$
$\underline{\mathbf{C}}$

fluid

nitrogen

air

air

line size, in 0.25

0.25

0.50

$\left(\mathrm{D}_{2}<\right.$ line i.d.)

$\begin{array}{lccc}\text { p, } \mathbf{l b} / \mathbf{f t}^{\mathbf{3}} & 0.075 & 0.075 & 0.075 \\ \text { q, scfm } & 2 & 2 & 10 \\ \mathbf{T}_{1},{ }^{\circ} \mathbf{F} & 60 & 70 & 70 \\ \text { p 1, psia } & 45 & 115 & 115\end{array}$

\section{Table 1}

The plates used for the testing had diameters of 0.099" (sharp edged orifice) and $0.0867 "$ (short tube orifice).

\section{ELOW TESTS}

Two sample plates were fabricated, sized for an expected flow rate of $10 \mathrm{scfm}$ at $100 \mathrm{psig}$ inlet pressure. Plate "A" was a sharp edged orifice plate and plate "B" was a short tube orifice plate. The tests were done with the help of D. Ostrowski using the set-up shown in Figure 1. 


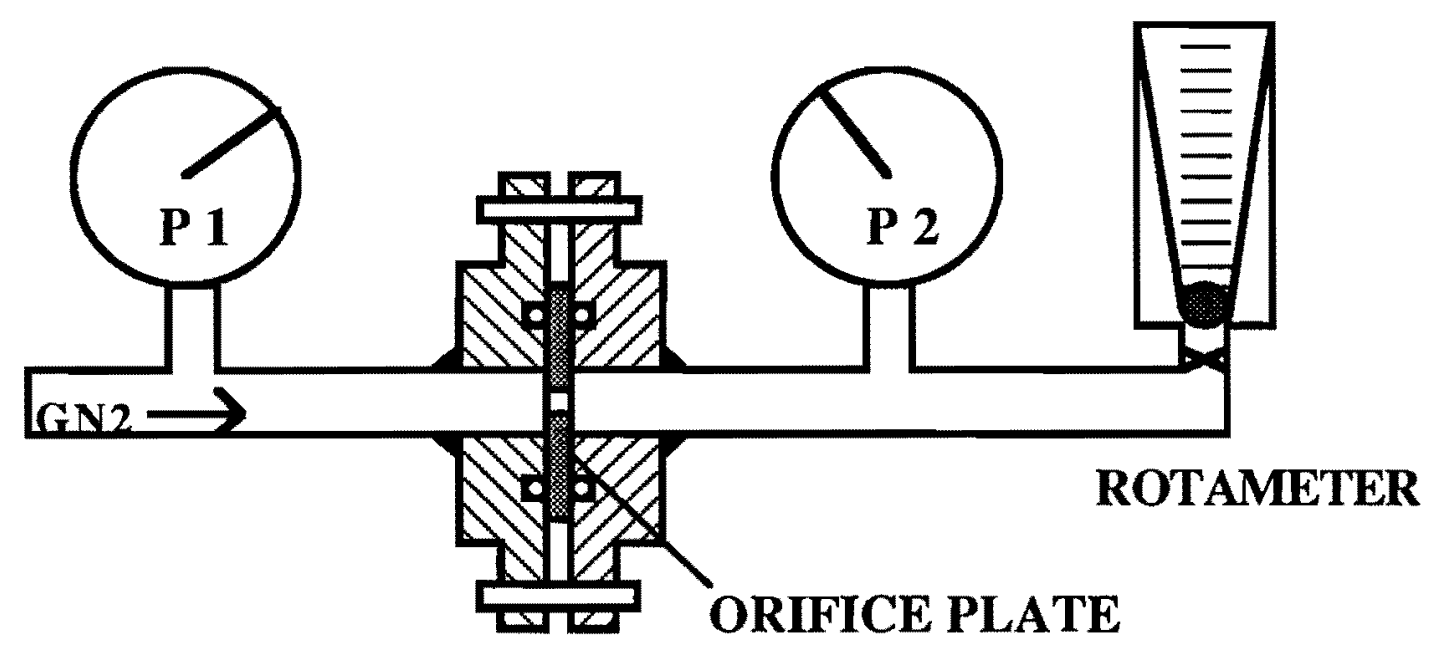

Figure 1

With the valve on the rotameter fully opened, the inlet pressure was gradually increased and the corresponding flow rates were recorded. This demonstrated that higher pressures result in higher flow rates. An inlet pressure of 100 psig produced a flow rate of $1000 \mathrm{scfh}(16.67 \mathrm{scfm})$ for plate "A" and a flow rate of $760 \mathrm{scfh}$ (12.67 scfm) for plate "B". Both of the observed flow rates were higher than the $10 \mathrm{scfm}$ value for which the orifices were sized. While a part of this difference in the values can be attributed to experimental error, e.g. rotameter and pressure gauge precision, the difference between the calculated and observed flow rates for plate "A" could be due to a geometry variance between the proposed design and the final machined piece. The discharge coefficient for a sharp edged orifice is 0.61 and that of a rounded edge orifice is 0.98 . Upon close examination of the orifice plate, the edge appears to have more of a rounded than a sharp edge quality. Inserting the higher discharge coefficient value of 0.98 into the previously used sizing equation yields a flow rate value of $16.17 \mathrm{scfm}$, which is in better accordance with the empirically obtained value.

The downstream pressure was varied by 5 psig increments by the valve on the rotameter to keep the inlet pressure constant, and the corresponding flow rates were recorded. The results for plates "A" and "B" are shown in Figures 2 and 3, respectively. When the downstream pressure was less than the critical flow pressure $\left(p_{2}<p_{m}=0.53 * p_{1}\right)$, the flow rate of the nitrogen gas did not change. This phenomenon was demonstrated for three different inlet pressures with each prototype plate. 


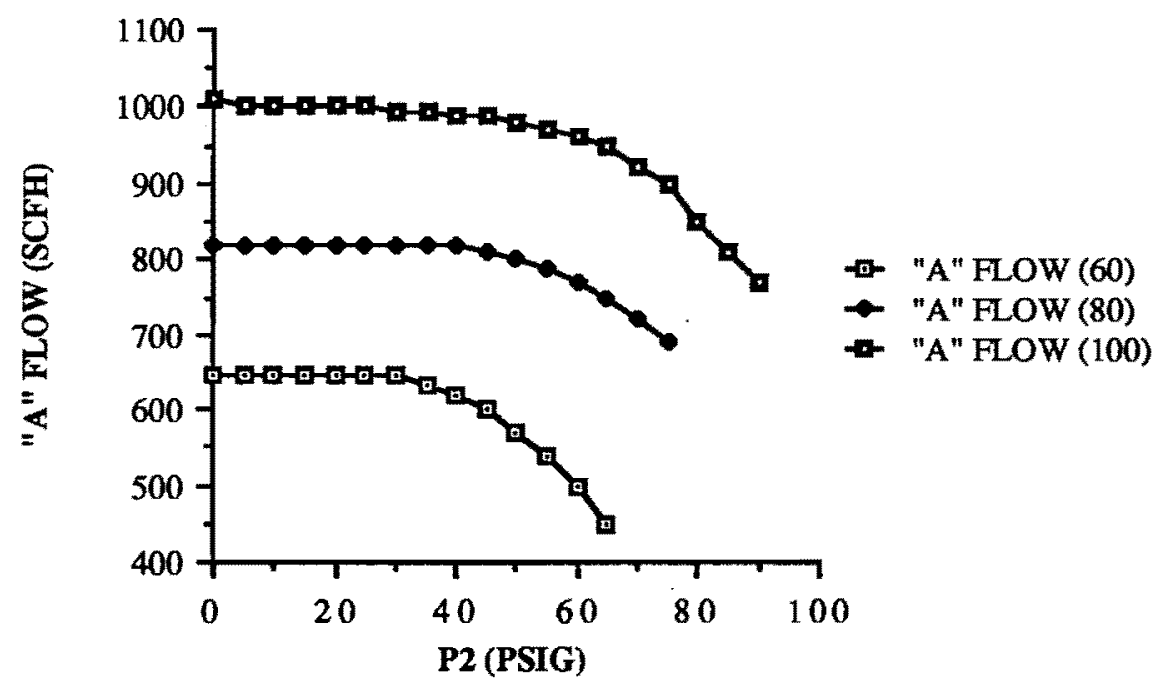

Figure 2

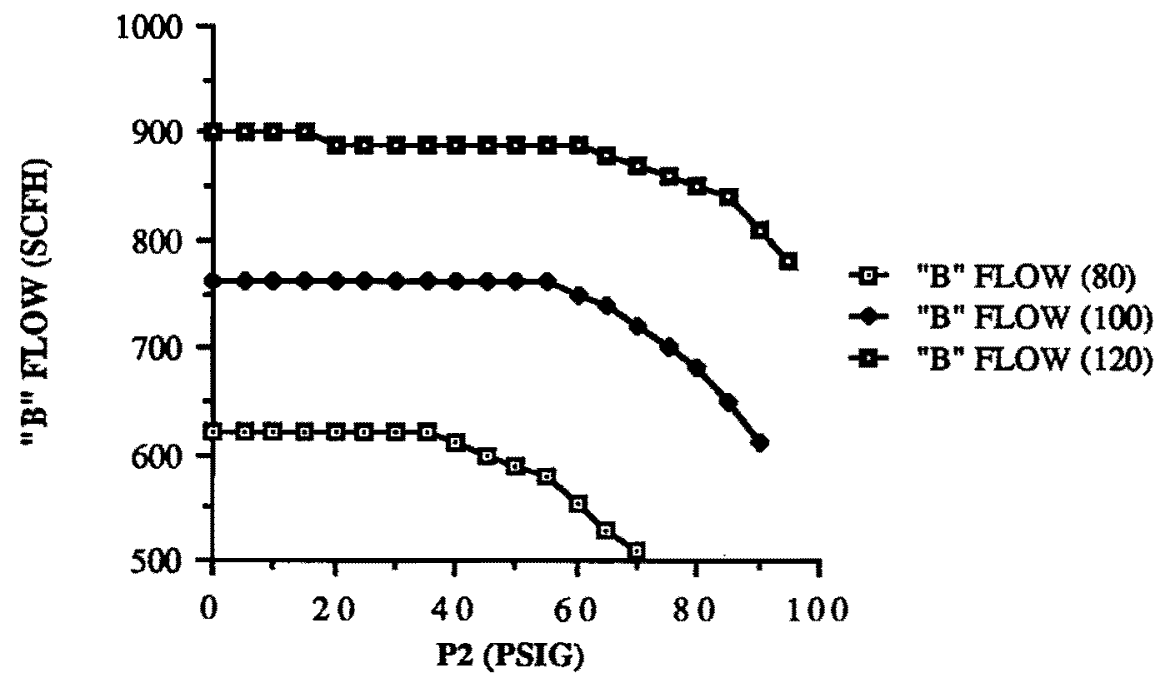

Figure 3 


\section{CONCLUSION}

Provided that the necessary orifice plates are machined in a manner similar to that of the prototypes, the orifices for the various lines were sized using the discharge coefficient for the round edge orifice because the calculated values were in good agreement with the empirically obtained values for this case. The final calculated orifice diameters for the round edge, sharp edge, and short tube cases are listed in Table 2.
$\underline{A}^{*}$
B
C

round edge
diameter
$0.0554 "$
$0.0349^{\prime \prime}$
$0.0783^{\prime \prime}$
drill size
54
65
47

sharp edge
diameter
$0.0703^{\prime \prime}$
$0.0442 "$
$0.0993^{\prime \prime}$
drill size
50
56
39

short tube
diameter
$0.0614^{\prime \prime}$
$0.0386^{\prime \prime}$
$0.0867^{\prime \prime}$
drill size
53
62
44

\section{Table 2}

* Note: A, B, and C refer to the three different flow cases presented in Table 1. 